\title{
Novel Approach to Repairing a Traumatic Aortic Arch Pseudoaneurysm Following a Fall
}

\author{
Azhar Hussain, BMBCh, MEd, MA (Cantab) ${ }^{1}$ Pouya Youssefi, MBBS, PhD ${ }^{1}$ Gopal Soppa, MBBS, PhD ${ }^{1}$ \\ Marjan Jahangiri, MBBS, MD ${ }^{1}$ \\ ${ }^{1}$ Department of Cardiothoracic Surgery, St. George's Hospital, \\ London, United Kingdom \\ AORTA 2019;7:15-17.

\begin{abstract}
Address for correspondence Marjan Jahangiri, MBBS, MD, Department of Cardiothoracic Surgery, St. George's Hospital, Blackshaw Road, London SW17 0QT, United Kingdom

(e-mail: marjan.jahangiri@stgeorges.nhs.uk).
\end{abstract}
Abstract
Keywords
- aorta
- pseudoaneurysm
- traumatic aneurysm

Traumatic pseudoaneurysms of the aortic arch are often treated with surgical repair regardless of the lesion size or age. The authors report a simple, less invasive surgical repair in a patient who sustained blunt aortic injury following a fall.

\section{Introduction}

Blunt trauma to the aortic arch can occur during road traffic accidents and falls from a significant height. These injuries are often due to a combination of direct compressive effects and indirect acceleration-deceleration forces placed on the aortic wall. The aortic isthmus is often the region where the greatest strain occurs, at the point of insertion of the ligamentum arteriosum, where up to $95 \%$ of ruptures occur. ${ }^{1,2}$ Repair using prosthetic grafts to replace the affected segment of the aorta has been the recommended surgical approach.,

\section{Case Presentation}

A 73-year-old lady presented with a fall down of 13 stairs at her home while intoxicated. Her past medical history was significant for chronic obstructive pulmonary disease and degenerative lumbar spinal disease. She was a lifelong smoker who was independent in her daily activities. She presented to her local hospital with symptoms of neck pain and stiffness but denied any chest pain. She was hemodynamically stable and underwent a computed tomography (CT) scan. The scan revealed no obvious vertebral fractures but did reveal a focal pseudoaneurysm along the left lateral wall of the aortic arch between the origins of the left common carotid and subclavian arteries ( $\mathbf{- F i g}$. 1). This measured $19 \mathrm{~mm}$ in maximum anteroposterior dimension. She was subsequently referred to the vascular surgical team, who agreed to manage her conservatively with yearly CT scans.
Eleven months later, the patient represented to her local hospital with sudden onset of chest pain radiating to her back. Initial observations were unremarkable. A repeat CT of the aorta demonstrated the aneurysm with no significant size increase compared with the previous CT scan. The vascular surgical team felt that an endovascular approach would not be suitable owing to the proximity of the lesion to the head and neck vessels. Transthoracic echocardiogram and coronary angiography were normal.

The patient underwent surgery via a median sternotomy. The aortic arch and the head and neck vessels were dissected. The pseudoaneurysm was identified and appeared isolated to the greater curve on the left lateral aspect of the arch (-Fig. 2). Following full heparinization, cardiopulmonary bypass was established by cannulation of the ascending aorta and the right atrium at a temperature of $35^{\circ} \mathrm{C}$. The base of the aneurysm was approximated using several $3 / 0$ prolene pledgeted mattress sutures from the outside, with reduced flow facilitating the closure (-Fig. 3). A needle was inserted into the excluded part of the aneurysm to ensure there was no persistent flow. The bypass time was 27 minutes. The patient's postoperative course was unremarkable. She was extubated on the same day and discharged home on the 5th postoperative day. She was reviewed in the outpatient follow-up clinic for 6 months and then at 1 year postoperatively. She was doing very well with no chest or back pain. A repeat CT scan at 6 months revealed an isolated saccular aneurysm which no longer filled with contrast ( - Fig. 4). The ascending aorta and descending thoracic aorta were normal. received

October 16, 2017

accepted after revision

February 22, 2019
DOI https://doi.org/

10.1055/s-0039-1687902. ISSN 2325-4637.
Copyright $\odot 2019$ by Thieme Medical Publishers, Inc., 333 Seventh Avenue, New York, NY 10001, USA. Tel: +1(212) 584-4662.
License terms

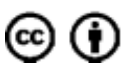




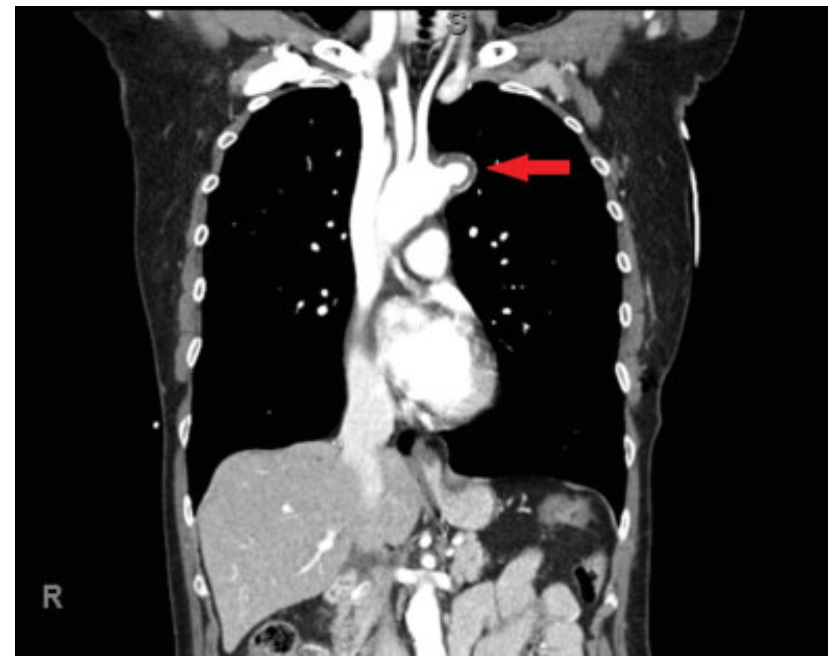

Fig. 1 Computed tomography (CT) aorta showing the pseudoaneurysm.

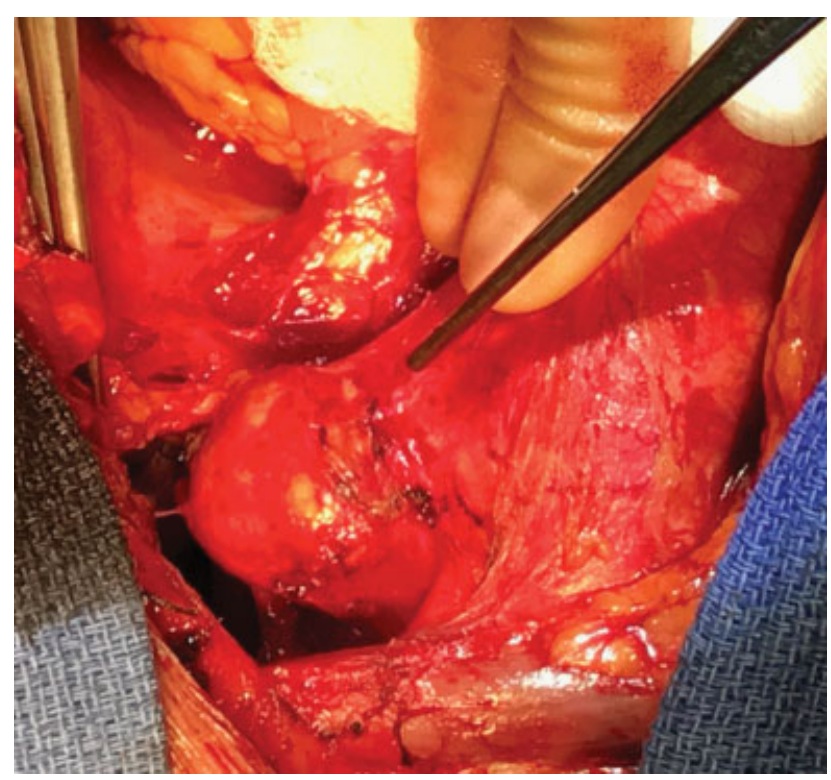

Fig. 2 Operative picture demonstrating the pseudoaneurysm.

A follow-up transthoracic echocardiogram revealed normal biventricular function and a normal sized aortic root.

\section{Discussion}

We have shown a simple and less invasive closure of a traumatic aortic pseudoaneurysm. To the best of our knowledge, this approach is not reported elsewhere in the literature. The traditional approach to repairing a traumatic aortic pseudoaneurysm of the arch typically involves deep hypothermic circulatory arrest which is associated with a high mortality and morbidity rate $(20-30 \%)$ in acute traumatic cases. ${ }^{5}$ Our approach also significantly reduces the cardiopulmonary bypass time and its associated risks. This case demonstrates that with careful surgical planning, an uncomplicated aortic pseudoaneurysm can be treated less

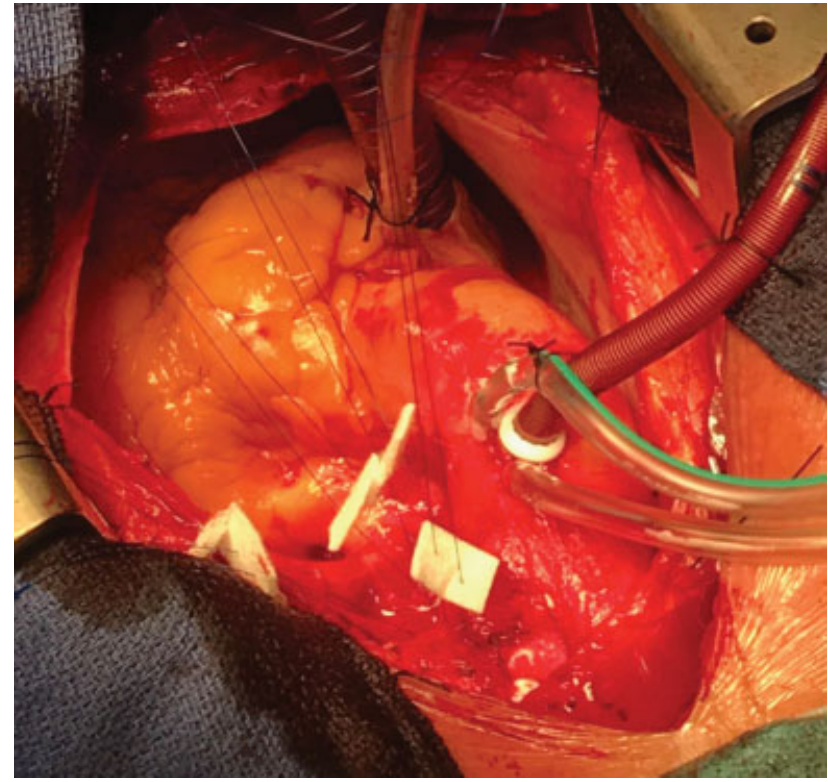

Fig. 3 Pledgeted mattress sutures used to close the base of the aneurysm.

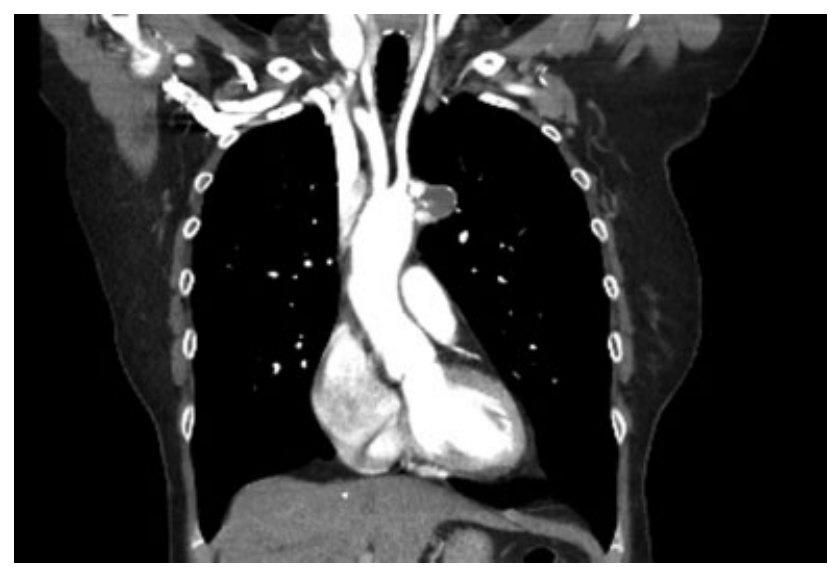

Fig. 4 Follow-up computed tomography (CT) aorta showing no contrast filling into the aneurysm.

invasively while reducing the risks associated with the conventional open aortic approach.

\section{Funding}

None.

\section{Conflict of Interest}

The authors declare no conflict of interest related to the article.

\section{Acknowledgment}

None.

\section{References}

1 Richens D, Kotidis K, Neale M, Oakley C, Fails A. Rupture of the aorta following road traffic accidents in the United Kingdom 1992-1999. The results of the co-operative crash injury study. Eur J Cardiothorac Surg 2003;23(02):143-148 
2 Siegel JH, Belwadi A, Smith JA, Shah C, Yang K. Analysis of the mechanism of lateral impact aortic isthmus disruption in real-life motor vehicle crashes using a computer-based finite element numeric model: with simulation of prevention strategies. J Trauma 2010;68(06):1375-1395

3 Prêtre R, Chilcott M. Blunt trauma to the heart and great vessels. $\mathrm{N}$ Engl J Med 1997;336(09):626-632
4 Chiba K, Abe H, Kitanaka Y, Miyairi T, Makuuchi H. Conventional surgical repair of traumatic rupture of the thoracic aorta. Gen Thorac Cardiovasc Surg 2014;62(12):713-719

5 Cardarelli MG, McLaughlin JS, Downing SW, Brown JM, Attar S, Griffith BP. Management of traumatic aortic rupture: a 30-year experience. Ann Surg 2002;236(04):465-469, discussion 469-470 